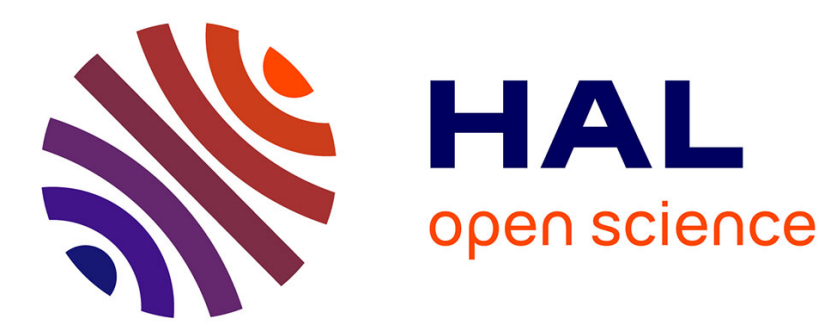

\title{
Plasma-enhanced C.V.D. of amorphous GexS1-x, and GexSe1-x films
}

\author{
E. Sleeckx, P. Nagels, R. Callaerts, M. van Roy
}

\section{To cite this version:}

E. Sleeckx, P. Nagels, R. Callaerts, M. van Roy. Plasma-enhanced C.V.D. of amorphous GexS1$\mathrm{x}$, and GexSe1-x films. Journal de Physique IV Proceedings, 1993, 03 (C3), pp.C3-419-C3-426. 10.1051/jp4:1993358 . jpa-00251415

\section{HAL Id: jpa-00251415 https://hal.science/jpa-00251415}

Submitted on 1 Jan 1993

HAL is a multi-disciplinary open access archive for the deposit and dissemination of scientific research documents, whether they are published or not. The documents may come from teaching and research institutions in France or abroad, or from public or private research centers.
L'archive ouverte pluridisciplinaire HAL, est destinée au dépôt et à la diffusion de documents scientifiques de niveau recherche, publiés ou non, émanant des établissements d'enseignement et de recherche français ou étrangers, des laboratoires publics ou privés. 


\title{
Plasma-enhanced C.V.D. of amorphous $\mathrm{Ge}_{x} \mathrm{~S}_{1_{-x}}$ and $\mathrm{Ge}_{x} \mathrm{Se}_{1_{-x}}$ films
}

\author{
E. SLEECKX, P. NAGELS, R. CALLAERTS and M. VAN ROY
}

RUCA, University of Antwerp, 2020 Antwerpen, Belgium

\begin{abstract}
We describe plasma-enhanced chemical vapour deposition for decomposing a mixture of two gaseous hydrides, $\mathrm{GeH}_{4}$ and $\mathrm{H}_{2} \mathrm{~S}$ or $\mathrm{H}_{2} \mathrm{Se}$, to yield layers of amorphous $\mathrm{Ge}_{\mathrm{x}} \mathrm{S}_{1-\mathrm{x}}$ and $\mathrm{Ge}_{\mathrm{x}} \mathrm{Se}_{1-\mathrm{x}}$. We discuss the influence of the gas ratios and the deposition conditions (pressure, if power input) on the chemical composition and homogeneity of the films. For Ge-Se samples, the composition varied between $\mathrm{Ge}$-rich (typically $\mathrm{Ge}_{0.66} \mathrm{Se}_{0.34}$ ) and Se-rich deposits (maximum $\mathrm{Ge}_{0.23} \mathrm{Se}_{0.77}$ ). The incorporation of sulfur was less effective : maximum 57 at. $\% \mathrm{~S}$ in Ge-S layers $\left(\mathrm{GeH}_{4} / \mathrm{H}_{2} \mathrm{~S}=1 / 96\right.$ and $\mathrm{p}=0.1$ mbar) i.e. less than the stoichiometric composition $\mathrm{GeS}_{2}$. Information concerning the structure of as-deposited Ge-S and Ge-Se layers was obtained from infrared and Raman spectroscopy. Ge-rich films of both Ge-S and Ge-Se were unstable in air and showed in their IR spectra broad absorption bands of Ge-O vibrations, increasing in intensity when keeping them in air for a long time.
\end{abstract}

\section{Introduction}

Amorphous chalcogenide semiconductors containing sulphur, selenium or tellurium show a wide variety of photo-induced changes in their chemical and physical properties when exposed to light having a photon energy comparable to the bandgap. Among these are reversible photostructural transformations which cause a shift in their optical absorption edge to lower energies (i.e. a "red shift") or higher energies ("blue shift"). These phenomena are known as photodarkening and photobleaching. The effects are typical of the amorphous state and are of scientific interest because they yield information on metastable structural states in the amorphous chalcogenides.

The photostructural changes have mainly been studied in thin films (of the order of $1 \mu \mathrm{m}$ thick) in two groups of materials : arsenic chalcogenides which represent a 3:2 coordinated system and germanium chalcogenides which belong to a 4:2 coordinated system. Most investigations have dealt with thin films prepared by thermal evaporation. In our study we have prepared films of amorphous $\mathrm{Ge}_{\mathrm{x}} \mathrm{S}_{1-\mathrm{x}}$ and $\mathrm{Ge}_{\mathrm{x}} \mathrm{Se}_{1-\mathrm{x}}$ by plasma-enhanced chemical vapour deposition, PECVD, a technique widely used for the preparation of amorphous silicon. We believe that PECVD is a promising technique for growing layers of amorphous chalcogenides, in particular with respect to their possible technological applications. Compared to thermal evaporation this deposition method has many advantages, including : - a broad range of chemical compositions in the case of binary systems, such as $\mathrm{Ge}_{\mathrm{x}} \mathrm{S}_{1-\mathrm{x}}$ and $\mathrm{Ge}_{\mathrm{x}} \mathrm{Se}_{1-\mathrm{x}}$; - a good reproducibility of a given chemical composition after optimization of the deposition conditions; - the possibility to change the morphology of the film depending on the deposition parameters, e.g. temperature, substrate bias; - the process can be easily industrialized.

By making use of the photo-induced phenomena, the amorphous chalcogenides are good 
candidates for many applications, e.g. media for optical imaging or storage and materials for IR transmission (from visible to beyond $15 \mu \mathrm{m}$ ). The metal photodissolution effect is probably the most useful application because it enables these materials to be used as photoresists in photolithography. This is based on the rapid diffusion of some metals, e.g. Ag, into the amorphous film under illumination and the difference in solubility between the illuminated and non-illuminated regions. In terms of resolution and linewith control the performance of these systems matches and even exceeds that of organic resists (submicron region). In recent years there has been considerable interest in the inorganic resist systems based on the photodoping of amorphous chalcogenide films. The majority of the work was devoted to Ge-Se films deposited by vacuum evaporation. This is one of the reasons why we selected the germanium chalcogenides for preparation by PECVD.

\section{Experimental procedures}

We have deposited thin films ( 1 to $2 \mu \mathrm{m}$ thick) in a plasma discharge stainless steel reactor, which was used in previous studies for the fabrication of amorphous silicon solar cells. The precursor gases were pure $\mathrm{GeH}_{4}$ and pure $\mathrm{H}_{2} \mathrm{~S}$ for the $\mathrm{Ge}-\mathrm{S}$ layers, or $\mathrm{GeH}_{4}$ and $\mathrm{H}_{2} \mathrm{Se}$ diluted in hydrogen (15 vol.\% of the hydrides) for the Ge-Se layers. A low pressure plasma (total gas pressure from 0.1 to 1 mbar) was created by an rf discharge $(13.56 \mathrm{MHz})$ between two parallel plate electrodes, $8 \mathrm{~cm}$ in diameter. The experimental arrangement consisting of the reactor, deposition control systems and pumps is shown schematically in Fig. 1. The reactant gases were mixed before entering the reactor and were admitted through an inlet in the reactor wall on the height of the electrodes. The gases were pumped away through an outlet at the opposite side, so that the gas flow was parallel to the electrodes. In all experiments the separation between the powered (top) and grounded electrode (bottom) was kept constant at $3 \mathrm{~cm}$. Gas flows were controlled by electronic mass flow controllers. The $\mathrm{GeH}_{4} /$ chalcogen hydride ratio expressed in volumes was varied from $1 / 2$ to $1 / 24$ for the $\mathrm{Ge}_{\mathrm{x}} \mathrm{Se}_{1-\mathrm{x}}$ system and from $1 / 6$ to $1 / 96$ for the $\mathrm{Ge}_{\mathrm{x}} \mathrm{S}_{1-\mathrm{x}}$ system. The total gas pressure was measured and automatically regulated through a butterfly valve by a Baratron pressure gauge. At high pressure (1 mbar) small dust particles were produced within the gas and were deposited on the bottom electrode and the reactor wall.

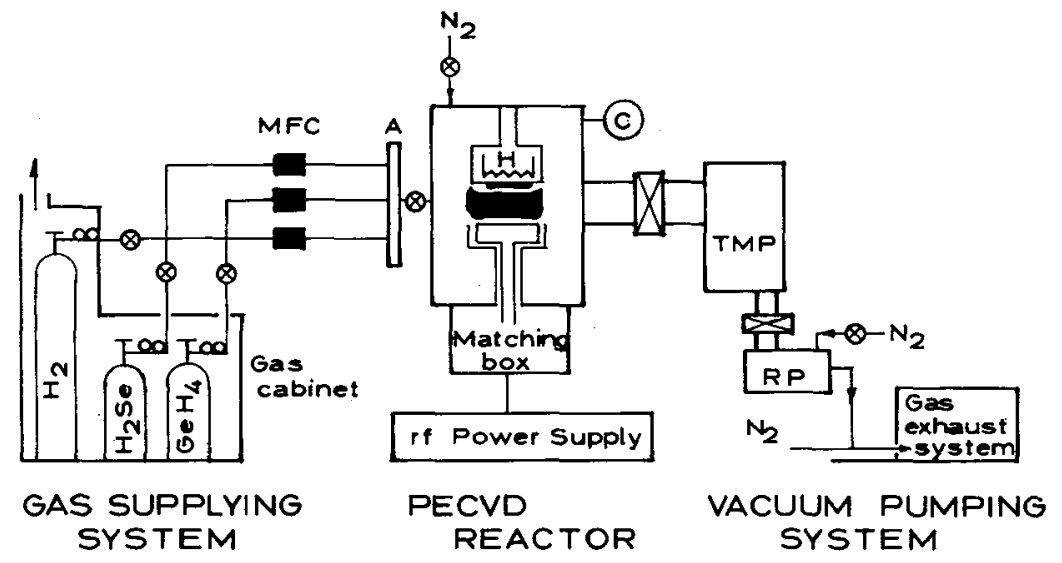

Fig. 1. Schematic of experimental arrangement used for plasma-enhanced chemical vapour deposition of amorphous Ge-S and Ge-Se layers.

$\begin{array}{llll}\otimes & \text { below seal valves } & \text { C } & \text { baratron } \\ \text { MFC } & \text { mass flow controller } & \text { V } & \text { throttle valve } \\ \text { A } & \text { mixing chamber } & \text { TMP } & \text { turbomolecular pump } \\ \text { H } & \text { heater } & \text { RP } & \text { rotary pump }\end{array}$


The rf power coupled into the reactor varied from 20 to $80 \mathrm{~W}$. Crystalline silicon and glass substrates were fixed on both electrodes. Depositions were made without additional heating of the substrates by a furnace. The deposition time varied between 15 and 45 minutes. The exhaust gases were passed through a furnace for decomposition and scrubbed in a solution of $\mathrm{KMnO}_{4}$.

\section{Characterization of samples}

\subsection{Chemical composition}

For determination of the chemical composition of the layers, a silicon platelet of approximate dimension $1 \times 2 \mathrm{~cm}^{2}$, cut from a wafer, was positioned from the middle to the gas inlet inside of both the grounded and powered electrode. The $\mathrm{Ge} / \mathrm{chalcogen}$ atomic ratio was measured in the middle of the platelet at regular distances of $1 \mathrm{~mm}$ by means of electron microprobe analysis.

\section{Ge-S system}

In a first series of runs the total gas pressure was kept constant at 0.1 mbar and the rf power input at $20 \mathrm{~W}$. The gas ratio $\mathrm{GeH}_{4} / \mathrm{H}_{2} \mathrm{~S}$ was varied from $1 / 6$ to $1 / 96$. The flow rate of germane was always $1 \mathrm{sccm}$. Figure 2 shows the germanium content in at.\% of layers deposited on the grounded electrode as a function of the position of the microprobe beam. It is clear that the incorporation of $\mathrm{S}$ was not very effective : for a $\mathrm{GeH}_{4} / \mathrm{H}_{2} \mathrm{~S}$ ratio equal to $1 / 96$ the chemical composition is about $\mathrm{Ge}_{0.43} \mathrm{~S}_{0.57}$, which is less sulfur rich than the stoichiometric composition $\mathrm{GeS}_{2}$. Over the relatively small area of measurement $(1 \mathrm{~cm}$ in length), the samples showed a rather good chemical homogeneity. The chemical composition of the $\mathrm{Ge}_{\mathbf{x}} \mathrm{S}_{1-\mathrm{x}}$ layers obtained for the various gas ratios is also listed in Table I.

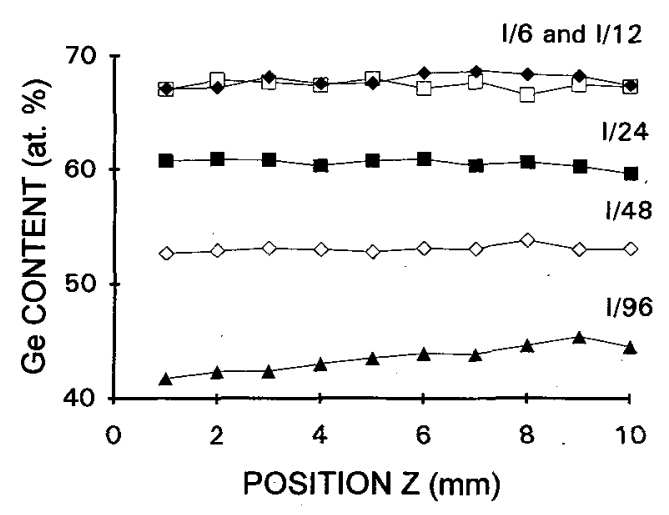

Fig. 2. Ge content of $\mathrm{Ge}_{\mathrm{x}} \mathrm{S}_{1-\mathrm{x}}$ layers measured over $10 \mathrm{~mm}$ distance $(\mathrm{z}=10 \mathrm{~mm}$ : middle of electrode) for various $\mathrm{GeH}_{4} / \mathrm{H}_{2} \mathrm{~S}$ gas ratios.

It is well known that, when depositing binary alloys by plasma CVD, the deposition conditions may effect to a large extent the final chemical composition. We studied the influence of gas pressure and rf power input using a constant gas ratio $\mathrm{GeH}_{4} / \mathrm{H}_{2} \mathrm{~S}$ equal to $1 / 24$ and a same flow rate. Figure 3 shows the microprobe analysis of two layers deposited at $p=0.1$ mbar and $p=0.6$ mbar, respectively (power $=20 \mathrm{~W}$ ). We observed that the increase in pressure from 0.1 to 0.6 mbar yielded a layer with a higher sulfur content. At high pressure the variation of the chemical composition is considerable, yielding a much higher $\mathrm{Ge}$ content closer to the gas inlet. 
Table I. Chemical composition of amorphous $\mathrm{Ge}_{\mathrm{x}} \mathrm{S}_{1-\mathrm{x}}$ and $\mathrm{Ge}_{\mathrm{x}} \mathrm{Se}_{1-\mathrm{x}}$ layers deposited on the grounded electrode at a pressure of 0.1 mbar.

\begin{tabular}{|c|c|c|c|c|c|c||}
\hline & \multicolumn{5}{|c||}{$\mathrm{GeH}_{4} / \mathrm{H}_{2} \mathrm{~S}\left(\mathrm{H}_{2} \mathrm{Se}\right.$ )(volume ratio) } \\
\cline { 2 - 7 } & $1 / 2$ & $1 / 6$ & $1 / 12$ & $1 / 24$ & $1 / 48$ & $1 / 96$ \\
\hline $\mathrm{x}$ in $\mathrm{Ge}_{\mathrm{x}} \mathrm{S}_{1-\mathrm{x}}$ & & 0.67 & 0.67 & 0.60 & 0.53 & 0.43 \\
\hline $\mathrm{Ge}_{\mathrm{x}} \mathrm{Se}_{1-\mathrm{x}}$ & 0.66 & 0.34 & 0.26 & 0.23 & & \\
\hline
\end{tabular}

In Fig. 4 the chemical analysis results are represented for samples prepared with the same gas ratio of $1 / 24$ and at the same pressure of $p=0.1$ mbar but with an increasing if power input from 20 to $80 \mathrm{~W}$. This resulted in a decrease of the Ge content of the layer.

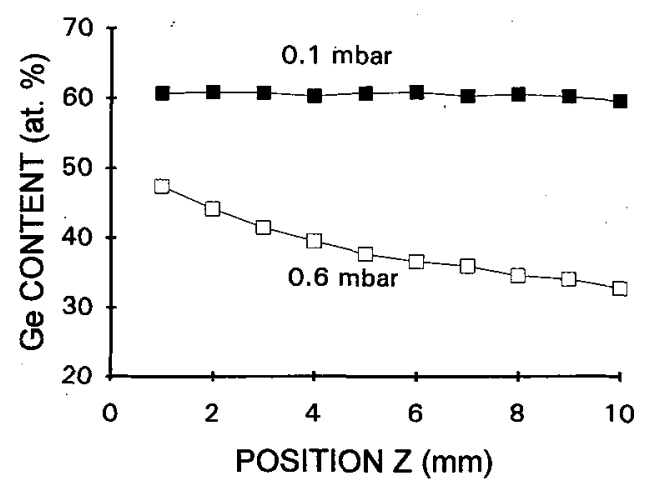

Fig. 3. Ge content of two Ge-S layers deposited at $0.1 \mathrm{mbar}$ and 0.6 mbar; $\mathrm{GeH}_{4} / \mathrm{H}_{2} \mathrm{~S}=1 / 24$ $(\mathrm{z}=10 \mathrm{~mm}$ : middle of electrode)

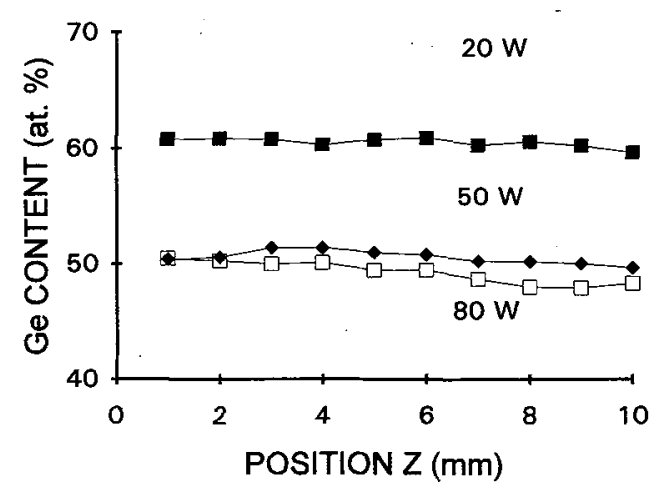

Fig. 4. Ge content of Ge-S layers for various rf power; $\mathrm{GeH}_{4} / \mathrm{H}_{2} \mathrm{~S}=$ $1 / 24$ and $p=0.1$ mbar ( $z=10 \mathrm{~mm}$ : middle of electrode)

\section{Ge-Se system}

As in the case of the Ge-S system, the influence of the $\mathrm{GeH}_{4} / \mathrm{H}_{2} \mathrm{Se}$ gas ratio, of the total gas pressure and the rf power input on the chemical composition was investigated. The microprobe results are shown in Fig. 5 for layers prepared with a $\mathrm{GeH}_{4} / \mathrm{H}_{2} \mathrm{Se}$ ratio varying from 1/2 to $1 / 24$ at a pressure of $0.1 \mathrm{mbar}$ and an rf power of $80 \mathrm{~W}$. The higher if power was used because the deposition rate was slower than in the case of the Ge-S system, due to the use of diluted reactants. As can be seen from Fig. 6, the power input (varied from 30 to $80 \mathrm{~W}$ ) had a minor effect on the chemical composition. For these two depositions the pressure was again held at 0.1 mbar and the $\mathrm{GeH}_{4} / \mathrm{H}_{2} \mathrm{Se}$ gas ratio was equal to $1 / 2$. Table I also lists the microprobe results for the $\mathrm{Ge}_{\mathrm{x}} \mathrm{Se}_{1-\mathrm{x}}$ layers deposited at $\mathrm{p}=0.1 \mathrm{mbar}$. For the Ge-Se system a much broader compositon range can be achieved, which is of interest for a study of photostructural changes in films with compositions varying from $\mathrm{GeSe}$ to $\mathrm{GeSe}_{3}$. In the Ge-Se system we observed the same influence of the pressure on the chemical composition as in Ge-S, i.e. a decrease of the Ge content with increasing gas pressure (see Fig. 7). 


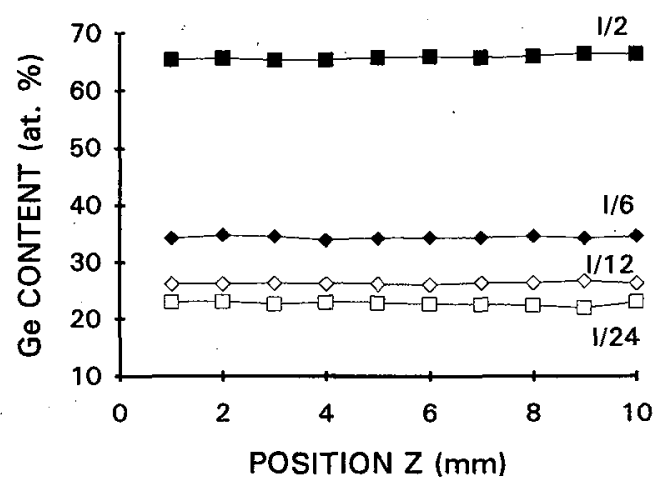

Fig. 5. Ge content of $\mathrm{Ge}_{\mathrm{x}} \mathrm{Se}_{1-\mathrm{x}}$ layers measured over $10 \mathrm{~mm}$ distance $(z=10 \mathrm{~mm}$ : middle of electrode) for various $\mathrm{GeH}_{4} / \mathrm{H}_{2} \mathrm{Se}$ gas ratios.

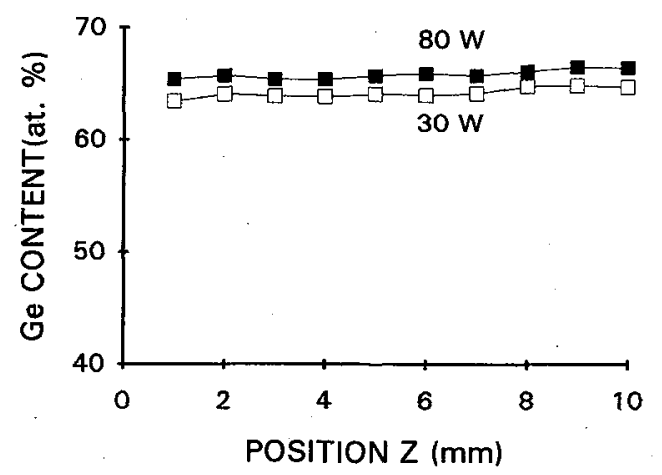

Fig. 6. Ge content of two Ge-Se layers deposited with 30 and $80 \mathrm{~W}$ if power; $\mathrm{GeH}_{4} / \mathrm{H}_{2} \mathrm{Se}=1 / 2$, $\mathrm{p}=0.1$ mbar.

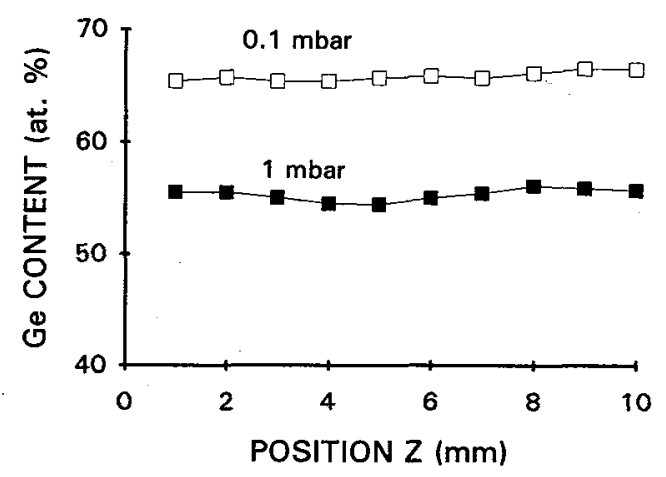

Fig. 7. Ge content of two Ge-Se layers deposited at $\mathrm{p}=0.1$ and $1 \mathrm{mbar} ; \mathrm{GeH}_{4} / \mathrm{H}_{2} \mathrm{Se}=1 / 2$, $80 \mathrm{~W}$ rf power.

\subsection{Infrared spectroscopy}

IR transmission spectra were recorded in the wavenumber range from 4000 to $150 \mathrm{~cm}^{-1} \mathrm{on}$ films deposited onto polished crystalline Si wafers. The measurements were performed at room temperature using a Beckman 4240 in the range from 4000 to $300 \mathrm{~cm}^{-1}$ and a Bruker IFV $113 \mathrm{~V}$ in the range from 300 to $150 \mathrm{~cm}^{-1}$. Infrared and Raman spectroscopy are useful tools to study the structure of the amorphous materials. Although the germanium chalcogenides have been intensively studied during the last fifteen years, the knowledge of their structure, especially of the Ge-rich and chalcogen-rich alloys, is still ambiguous.

Both amorphous $\mathrm{GeSe}_{2}$ and $\mathrm{GeS}_{2}$ have a tetrahedral $\mathrm{XY}_{4}$-type local structure. The ordening of the tetrahedral molecules can be explained by different models. In the chemically ordered random network model Tronc et al. [1] proposed randomly bonded $\mathrm{GeSe}_{4 / 2}$ (or $\mathrm{GeS}_{4 / 2}$ ) tetrahedra linked to form a three dimensional network. The second model (raft model) proposed by Phillips [2], also has an array of $\mathrm{GeSe}_{4 / 2}$ tetrahedra, but these units are covalently bonded together in layers having atomic arrangements which are similar to the layers of 
crystalline $\mathrm{GeSe}_{2}[2,3]$. Since both models are composed of $\mathrm{GeSe}_{4 / 2}$ tetrahedra, the four vibrational normal modes of a $\mathrm{XY}_{4}$ tetrahedral molecule should be observed :

$v\left(A_{1}\right), v_{2}(E), v_{3}\left(F_{2}\right)$ and $v_{4}\left(F_{2}\right)[4]$. In Ge-rich or chalcogen-rich films homopolar bonds must be present.

A study by Drchal et al. [5] demonstrated that the structure of amorphous GeS is also represented by a $4: 2$ coordinated system with random statistics of $\mathrm{Ge}\left(\mathrm{Ge}_{4-\mathrm{n}} \mathrm{S}_{\mathrm{n}}\right)$ tetrahedra.

Figure 8 shows infrared spectra of a $\mathrm{Ge}_{0.30} \mathrm{~S}_{0.70}$ layer (a) $\left(\mathrm{GeH}_{4} / \mathrm{H}_{2} \mathrm{~S}=1 / 24, \mathrm{p}=0.6 \mathrm{mbar}\right.$ and $20 \mathrm{~W})$ and $\mathrm{a} \mathrm{Ge}_{0.50} \mathrm{~S}_{0.50}$ layer (b) $\left(\mathrm{GeH}_{4} / \mathrm{H}_{2} \mathrm{~S}=1 / 24, \mathrm{p}=0,1 \mathrm{mbar}\right.$ and $\left.50 \mathrm{~W}\right)$. The absorption band at $610 \mathrm{~cm}^{-1}$ observed in all spectra arises from the crystalline silicon substrate. The strong absorption around $370 \mathrm{~cm}^{-1}$ is the most characteristic feature of the Ge-S system. It is usually assigned to the stretching vibration of the $\mathrm{GeS}_{4}$ tetrahedral unit ( $v_{3}$ mode).

The absorption band at $260 \mathrm{~cm}^{-1}$ (see Fig. 9) observed in a $\mathrm{Ge}_{0.34} \mathrm{Se}_{0.66}$ layer (a) $\left(\mathrm{GeH}_{4} / \mathrm{H}_{2} \mathrm{Se}=\right.$ $1 / 6, \mathrm{p}=0.1 \mathrm{mbar}$ and power $=80 \mathrm{~W})$ and in $\mathrm{a} \mathrm{Ge}_{0.64} \mathrm{Se}_{0.36}$ layer $(\mathrm{b})\left(\mathrm{GeH}_{4} / \mathrm{H}_{2} \mathrm{Se}=1 / 2, \mathrm{p}=0.1\right.$ mbar and power $=30 \mathrm{~W}$ ) is due to the $v_{3}$ mode of the $\mathrm{GeSe}_{4}$ tetrahedra.

The IR spectra showed that samples with compositions around stoichiometry or with an excess of $\mathrm{S}$ or Se compared with $\mathrm{GeS}_{2}$ or $\mathrm{GeSe}_{2}$ were hydrogenated preferentially to $\mathrm{S}$ or Se atoms :

$\mathrm{S}-\mathrm{H}$ and Se-H stretching modes were observed at 2510 and $2200 \mathrm{~cm}^{-1}$, respectively. In samples with overstoichiometry of Ge small bands appeared at 2050,825 and $765 \mathrm{~cm}^{-1}$ (the two latter ones are seen in spectrum $c$ of Fig. 8). They were assigned to the bond stretching, the scissors and the wagging vibration of a polygermane $\left(\mathrm{GeH}_{2}\right)_{\mathrm{n}}$ - unit [6].

Previous studies, mainly on photostructural changes in amorphous $\mathrm{GeS}_{2}$ have demonstrated that the germanium chalcogenides are very sensitive to oxidation. We recorded the IR spectra of the $\mathrm{Ge}-\mathrm{S}$ and $\mathrm{Ge}-\mathrm{Se}$ layers after exposure to air for several weeks.

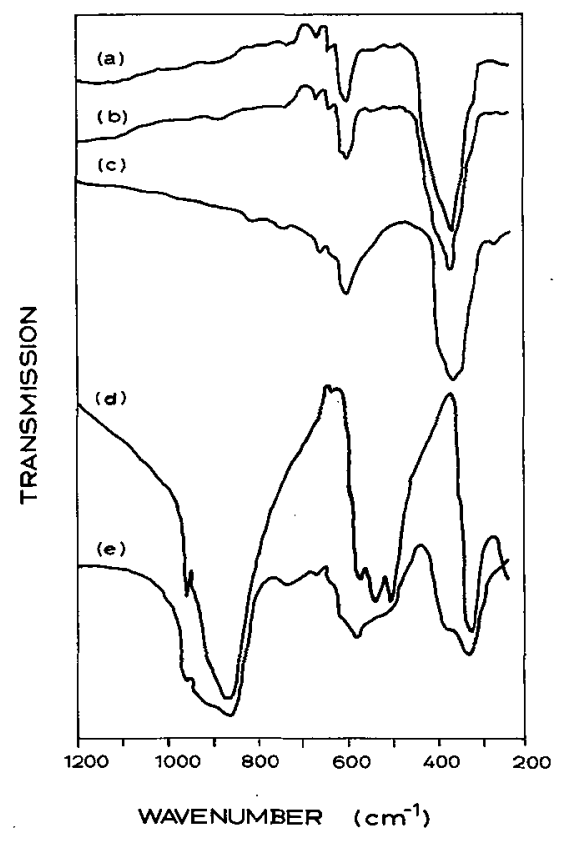

Fig. 8. Infrared spectra of Ge-S layers as-deposited and after exposure to air; (a) $\mathrm{Ge}_{0.30} \mathrm{~S}_{0.70}$ as-deposited (b) $\mathrm{Ge}_{0.30} \mathrm{~S}_{0.70}$ after air exposure; (c) $\mathrm{Ge}_{0.50} \mathrm{~S}_{0.50}$ as deposited (e) after air exposure; (d) crystalline $\mathrm{GeO}_{2}$. 
The result is shown in Fig. 8 for the Ge-S system. As can be seen, the Ge-rich film (spectrum e) showed after air exposure strong absorption bands in a broad range originating from Ge-O vibrations. We observed that the intensity of the bands strongly increased with prolonged exposure in air. In the same figure the IR absorption spectrum of crystalline $\mathrm{GeO}_{2}$ is represented (curve d). By comparing the spectra of the oxidized $\mathrm{Ge}-\mathrm{S}$ film and the one of $\mathrm{GeO}_{2}$, it is clear that the absorption bands observed in the Ge rich film are a consequence of the formation of $\mathrm{GeO}_{2}$ units. They show three typical vibrations around 860,550 and $330 \mathrm{~cm}^{-1}$, assigned to bond stretching, bond bending and bond rocking vibrations of local atomic arrangements in $\mathrm{GeO}_{2}$ [5]. The appearance of the strong absorption band at $330 \mathrm{~cm}^{-1}$ due to the rocking vibration of the $\mathrm{GeO}_{2}$ unit was also accompanied by a strong decrease of the typical stretching vibration of the $\mathrm{GeS}_{2}$ unit $\left(370 \mathrm{~cm}^{-1}\right)$ (see Fig. 8). This indicated that the density of the Ge-S bonds decreased upon oxidation and that during this process the matrix of the film was strongly destroyed leading to the formation of the $\mathrm{GeO}_{2}, \mathrm{SO}_{\mathrm{x}}$ and $\mathrm{H}_{2} \mathrm{~S}$. The formation of $\mathrm{SO}_{\mathrm{x}}$ and $\mathrm{H}_{2} \mathrm{~S}$ cannot be detected due to their high vapour pressure at room temperature. The IR spectrum of a Ge-S sample with chemical composition close to stoichiometry revealed that this material is much less sensitive to oxygen incorporation after air exposure (curve b in Fig. 8).

Analogous changes in the IR spectrum of the Ge-Se system were found after air exposure.

\subsection{Raman spectroscopy}

In Fig. 10 the Raman spectra of an as-deposited $\mathrm{Ge}_{0.34} \mathrm{Se}_{0.66}$ film $(\mathrm{p}=0.1 \mathrm{mbar}$, if power $=80 \mathrm{~W}$, $\mathrm{GeH}_{4} / \mathrm{H}_{2} \mathrm{Se}=1 / 6$ ) is shown (curve a). We observed 5 significant bands : a band at $200 \mathrm{~cm}^{-1}$ accompanied by a side band around $210-220 \mathrm{~cm}^{-1}$, a peak at $188 \mathrm{~cm}^{-1}$, a broad band at $280 \mathrm{~cm}^{-1}$, and a peak at $175 \mathrm{~cm}^{-1}$. As previously mentioned the structure of $\mathrm{GeSe}_{2}$ is composed of tetrahedral units. This explains the sharp mode at $200 \mathrm{~cm}^{-1}$ as the $A_{1}$ symmetric breathing mode. The intense mode at $220 \mathrm{~cm}^{-1}$, usually labelled as $A_{1}^{c}$, the companion of the $A_{1}$ mode, has been the subject of some controversy. The two modes at 200 and $220 \mathrm{~cm}^{-1}$ are the only ones observed in the Raman spectrum of a $\mathrm{Ge}_{0.26} \mathrm{Se}_{0.74}$ layer (curve c). Nemanich and Solin [7] constructed a model with clusters of 12 atom rings of $\mathrm{Ge}_{6} \mathrm{Se}_{6}$, which are embedded in a perfectly chemically ordered network. They suggested that the companion line is associated with the symmetric breathing mode of the "necklace" or ring of $\mathrm{Ge}_{6} \mathrm{Se}_{6}$ atoms. Bridenbaugh et al. [8] on the other hand proposed that chemical order is intrinsically broken in the stoichiometric system. They suggested that two kinds of partially polymerized clusters are present which are either cation-rich or chalcogen-rich. The latter were proposed to the raft-like fragments of the high temperature crystalline form and were laterally bordered by chalcogen-chalcogen bonds. These authors identified the $A_{1}^{c}$ mode as the local "edge modes" associated with dimerized chalcogens. Sugai [9] proposed to assign the $A_{1}$ and $A_{1}^{c}$ peaks to the localized modes at the corner and edge-sharing bonds of the tetrahedral molecules respectively. The bands at $280 \mathrm{~cm}^{-1}$ and 175 $\mathrm{cm}^{-1}$ observed in curve (a) were assigned to the vibrational modes of a structural unit containing $\mathrm{Ge}-\mathrm{Ge}$ bonds such as an ethane-like $\mathrm{Ge}\left(\mathrm{Se}_{1 / 2}\right)_{6}$ cluster [10]. The peak at $188 \mathrm{~cm}^{-1} \mathrm{can}$ be associated with the vibration of selenium atoms in a tetrahedral molecule in which a selenium atom is replaced by a germanium atom [11].

The $\mathrm{Ge}_{0.34} \mathrm{~S}_{0.66}$ film was annealed at $300^{\circ} \mathrm{C}$ for 1 hour in nitrogen atmosphere. The Raman spectrum recorded after heating (curve $b$ in Fig. 10) suggests that structural changes have occurred : the intensity of all the bands associated with Ge-Ge bonds has decreased. The new spectrum resembles that of the $\mathrm{Ge}_{0.26} \mathrm{Se}_{0.74}$, which is less germanium rich.

\section{Conclusion}

PECVD is a promising technique for preparing amorphous $\mathrm{Ge}_{\mathbf{x}} \mathrm{Se}_{1-\mathrm{x}}$ layers in a very broad composition range. The incorporation of sulfur in Ge-S layers is limited to approximately $\mathrm{Ge}_{0.33} \mathrm{~S}_{0.67}$, i.e. comparable to the stoichiometric composition $\mathrm{GeS}_{2}$. Germanium-rich $\mathrm{Ge}-\mathrm{Se}$ and $\mathrm{Ge}-\mathrm{S}$ layers are easily oxidized in air. 


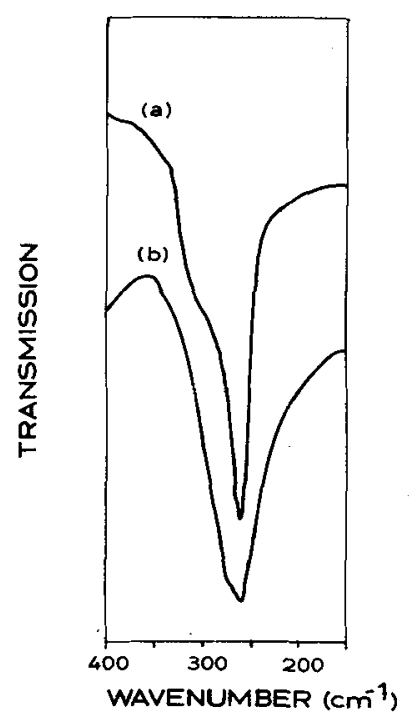

Fig. 9. Infrared spectra of a $\mathrm{Ge}_{0.34} \mathrm{Se}_{0.66}$ (a) and a $\mathrm{Ge}_{0.64} \mathrm{Se}_{0.36}$ (b) layer

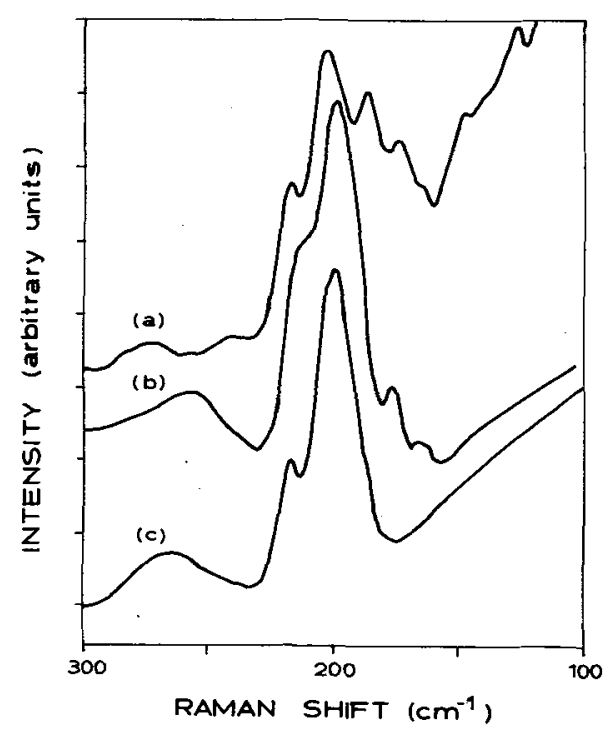

Fig. 10. Raman spectra of a $\mathrm{Ge}_{0.34} \mathrm{Se}_{0.66}$ layer: (a) as-deposited, (b) after annealing

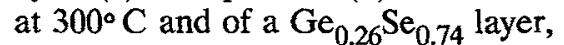
as-deposited (c)

\section{Acknowledgment}

The authors are indebted to Prof. H. Desseyn and Prof. B. Van der Veken for the use of the farinfrared and Raman spectrometer. They wish to thank Prof. R. Gijbels for the measurement of the chemical composition by electron microprobe. This work was funded by the Belgian National Science Foundation (I.I.K.W.).

\section{References}

[1] P. TRONC, M. BENSOUSSAN and A. BRENAC, Phys. Rev. B 8 (1973) 5947.

[2] J.C. PHILLIPS, J. Non-Cryst. Solids, 43 (1981) 37.

[3] P. BOOLCHAND, J. GROTHAUS, W.J. BRESSER and P. SURANYI, Phys. Rev. B 25 (1982) 2975.

[4] N. KUMAGAI, J. SHIRAFUJI and Y. INUISHI, J. Phys. Soc. Japan 42 (1977) 1262.

[5] V. DRCHAL and J. MALEK, Phil. Mag B, 58 (1988) 303.

[6] G. LUCOVSKY, S.S. CHAO, J. YANG, J.E. TYLER, R.C. ROSS and W. CZULATYJ, Phys. Rev. B, 31 (1985) 2190.

[7] R.J. NEMANICH, S.A. SOLIN, and G. LUCOVSKY, Solid State Commun. 21 (1977) 273.

[8] P.M. BRIDGENBAUCH, G.P. ESPINOSA, J.E. GRIFFITHS, J.C. PHILLIPS and J.P. REMEIKA, Phys. Rev. B, 20 (1979) 4140.

[9] S. SUGAI, Phys. Rev. B, 35 (1987) 1345.

[10] R.J. NEMANICH, G.A.N. CONNELL, T.M. HAYES and R.A. STREET, J. Phys. Rev. B, 18 (1978) 6900.

[11] H. KAWAMURA, M. MATSUMURA and S. USHIODA, J. Non-Cryst. Solids, $\underline{35} \& \underline{36}$ (1980) 1215. 